\title{
Pengujian Usability Heuristic Terhadap Perangkat Lunak Pembelajaran Matematika
}

\author{
Dinny Komalasari ${ }^{1}$, Maria Ulfa ${ }^{2}$ \\ ${ }^{1,2}$ Universitas Bina Darma, Palembang \\ E-Mail: ${ }^{1}$ dinny.komalasari@binadarma.ac.id, ${ }^{2}$ maria.ulfa@binadarma.ac.id
}

\begin{abstract}
ABSTRAK
Heuristic evaluation merupakan teknik pengujian dengan tujuan untuk mengukur tingkat kebergunaan sebuah aplikasi. Pengujian heuristic sendiri dalam proses pelaksanaannya dilakukan dengan melibatkan ahli. Dalam melakukan pengujian heuristic terdapat sepuluh pernyataan yang menjadi instrumen pengujian. Sepuluh instrumen tersebut dijawab oleh dengan lima kriteria penilaian yaitu 0 yang berarti tidak adalah masalah usability, 1 yang berarti memiliki cosmetic problem, 2 yang berarti aplikasi memiliki minor usability problem, 3 yang berarti memiliki major usability problem dan 4 yang berarti aplikasi memiliki usability catastrophe. Di dalam penelitian ini dilakukan pengujian terhadap aplikasi pembelajaran matematika sekolah dasar. Mengingat pentingnya aplikasi ketika digunakan oleh siswa maka penguji yang terlihat terdiri dari ahli teknologi informasi sebanyak tida orang ahli dan ahli mata pelajaran matematika sekolah dasar (guru) sebanyak dua orang. Dari hasil pengujian menunjukkan bahwa aplikasi secara umum tidak ada masalah usability atau mendapatkan nilai dengan pembulatan 0 . Namun terdapat dua bagian yang perlu dicermati bagi pengembang yaitu pernyatan nomor tujuh dan pernyataan nomor sembilan yaitu flexibility and efficiency of use dan help users recognize, diagnose, and recover from errors yang mendapatkan penilaian 1. Dari hasil pengujian maka dikatakan bahwa pengembang aplikasi dapat melakukan publikasi aplikasi karena tidak ada masalah yang signifikan dalam hal usability pada aplikasi.
\end{abstract}

\section{Kata kunci-pengujian usability, heuristic evaluation, aplikasi mobile}

\begin{abstract}
Heuristic evaluation is a testing technique with the aim of measuring the level of usefulness of an application. Heuristic testing itself in the implementation process is done by involving experts. In conducting heuristic testing there are ten statements that become testing instruments. The ten instruments were answered by five assessment criteria, 0 which means no is a usability problem, 1 which means having a cosmetic problem, 2 which means the application has a minor usability problem, 3 which means having a major usability problem and 4 which means the application has a usability catastrophe. In this study, testing of elementary school mathematics learning applications was carried out. Considering the importance of the application when used by students, the examiners that appear to consist of as many information technology experts are as many experts and two elementary school mathematics teachers (teachers). From the test results show that the application in general there is no usability problem or get a value with rounding 0 . However, there are two parts that need to be observed for developers, namely statement number seven and statement number nine, namely flexibility and efficiency of use and help users recognize, diagnose, and recover from errors that get a rating 1. From the test results it is said that the application developer can publish the application because there is no significant problem in terms of usability in the application.
\end{abstract}

\section{Keywords - usability testing, heuristic evaluation, mobile application}

Author Korespondensi (Dinny Komalasari)

Email : dinny.komalasari@binadarma.ac.id 


\section{PENDAHULUAN}

Upaya pemerintah kecerdasan kehidupan berbangsa dan bernegara dilakukan salah satu uapaya dilakukan melalui pendidikan. Sebagai bentuk keserius tersebut tercermin pada anggaran pendapatan dan belanja negara Republik Indonesia sesuai dengan undang-undang nomor 20 tahun 2003 dinyatakan bahwa anggaran pendidikan minimal dua puluh persen $(20 \%)$ dari total anggaran pendapatan dan belanja negara [1]. Kondisi tersebut juga berlaku untuk pemerintah tingkat satu dan pemerintah tingkat dua yang dalam hal ini pemerintah provinsi dan pemerintah kabupaten/kota yang harus mengalokasikan anggaran pendapatan dan belanja daerah sebesar dua puluh persen pula [2]. Namun hal yang tak kala penting dari upaya pemenuhan pendidikan adalah proses pembelajaran. Pembelajaran adalah sebuah kegiatan transfer pengetahuan melalui komunikasi yang dilakukan antara peserta didik dan pengajar untuk menyampaikan materi pelajaran. Pembelajaran juga merupakan aktivitas dengan tujuan untuk memberikan pendidikan kepada peserta didik [3]. Untuk melaksanakan proses pembelajaran terdapat metode penyampaian agar materi pembelajaran dapat diterima dengan baik. Penggunaan metode penyampaian materi pembelajaran juga harus mudah dimengerti sehingga ketika pengajar atau guru dapat dengan mudah mentransfer materi kepada peserta [4].

Salah satu materi pembelajaran pada dunia pendidikan yang menjadi fokus setiap sekolah adalah mata pelajaran matematika. Kondisi tersebut saat ini terjadi mulai dari tingkat sekolah dasar, sekolah menengah pertama sampai dengan sekolah menengah atas. Pelajaran matematika salah satu pelajaran yang memiliki unsur dan bagian untuk mendidik siswa dalam memahami teknologi, berfikir logis dan sistematis [5]. Untuk itu tidak sedikit saat ini aplikasi disediakan untuk belajar matematika. Diantara aplikasi tersebut adalah aplikasi ruang guru, dimana aplikasi ini dibuat berbasis mobile yang memiliki pengguna lebih dari sepuluh juta [6]. Aplikasi lain juga yang digunakan untuk pembelajaran adalah aplikasi matematika bangun ruang yang dikembangkan berbasis multimedia [7], dimana aplikasi jenis ini berjalan stay alone pada komputer atau perangkat mobile yang dapat menjalankan flash [8]. Selain dari kedua jenis aplikasi tersebut terdapat juga berbagai aplikasi lain yang digunakan sebagai media pembalajaran khususnya mata pelajaran matematika seperti aplikasi matematika kelas enam sekolah dasar. Aplikasi ini dibangun guna untuk membantu siswa sekolah dasar khususnya kelas enam untuk memahami materi pelajaran yang telah disampaikan oleh guru di sekolah. Namun aplikasi ini belum dipublikasikan secara luas mengingat membutuhkan masukan dari para ahli agar memiliki dampak yang luas bagi pengguna terutama anak sekolah dasar kelas enam. Masukan ahli yang dimaksud adalah ahli teknologi informasi dan guru yang mengajarkan mata pelajaran matematika khususnya matematika untuk kelas enam sekolah dasar dan ahli teknologi informasi.

Untuk melakukan evaluasi ahli terhadap sebuah aplikasi atau perangkat lunak dapat dilakukan dengan cara pengujian usability. Pengujian usability sendiri merupakan pengujian yang dilakukan dengan tujuan untuk melihat dan menganalisa tingkat kebergunaan dari sebuah perangkat lunak atau aplikasi [9]. Untuk melakukan pengujian terdapat berbagai macam teknik pengujian diantaranya adalah system usability scale dan heuristic evaluation [10]. Dalam melakukan pengujian usability biasanya fokus pengujian melihat lima aspek yaitu kemudahan aplikasi untuk dipelajari: efesiensi aplikasi, memorability pengguna ketika menggunakan aplikasi, error pada aplikasi dan kepuasan penggguna [11]. Pengujian dengan teknik system usability scale adalah pengujian usability yang menekankan pada perspektif pengguna aplikasi dalam melakukan pengujian, sedangkan pengujian heuristic evaluation adalah pengujian usability yang menekankan pada perspektif ahli dalam menilai aplikasi yang diuji [12]. Ada beberapa kelebihan untuk masingmasing teknik pengujian, system usability memiliki kelebihan diantaranya (1) dapat dengan 
mudah dimengerti oleh penguji (responden), (2) tidak memerlukan jumlah penguji yang banyak namun memiliki akurasi yang tinggi, (3) hasil pengujian dapat terlihat untuk membedakan aplikasi yang memiliki nilai kebergunaan atau tidak. Sedangkan heuristic evaluation memiliki kelebihan diantaranya (2) dapat dengan cepat mendapatkan informasi umpan balik dan murah, (2) perbaikan dapat segera dilakukan, (3) dapat dilakukan dengan teknik pengujian lain, dan (4) mendeteksi masalah kebergunaan pada aplikasi secara dini [13].

Untuk itu agar dapat mengetahui bagaimana pandangan ahli baik dari sisi guru yang mengajarkan mata pelajaran matematika dan juga ahli teknologi informasi terhadap aplikasi matematika anak sekolah dasar kelas enam, maka di dalam penelitian ini akan dilakukan pengujian ahli. Pendekatan yang digunakan adalah pengujian usability dengan teknik pengujian heuristic evaluation. Penggunaan teknik heuristic evaluation sendiri disebabkan teknik pengujian ini dikhususkan untuk pengujian aplikasi yang dinilai oleh ahli. Heuristic evaluation sendiri telah digunakan diberbagai pengujian aplikasi diantaranya aplikasi stocking pada perusahaan suku cadang Toyota Palembang [14], aplikasi pemesanan layanan taksi [15], dan pengujian website institusi pendidikan [16]. Melihat kondisi tersebut maka penggunaan heuristic evaluation dalam melakukan pengujian ahli sangatlah tepat agar mendapatkan masukan yang objektif sebelum aplikasi di launching ke publik untuk digunakan secara luas.

\section{METODOLOGI}

Untuk melakukan pengujian usability dengan teknik heuristic evaluation terhadap perangkat lunak Pembelajaran matematika maka proses atau langkah-langkah penelitian seperti pada Gambar 1.

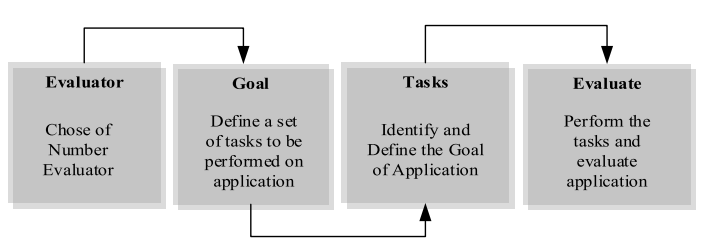

Gambar 1. Langkah-Langkah Penelitian [13]

Sesuai degan Gambar 1 dapat dijeaskan bahwa proses penelitian dimulai dari (1) memilih jumlah evaluator (expert) dalam hal ini menentukan siapa saja yang menjadi evaluator atau ahli sebagai penguji, (2) menentukan tugas yang harus dikerjakan oleh evaluator yang nantinya akan menjadi objek penilaian. (3) mengidentifikasi tujuan dari objek yang diuji baik atau dengan kata lain melihat kesesuaian antara tujuan dengan aplikasi yang dihasilkan, dan (4) melakukan pengujian atau evaluasi berdasarkan instrumen pengujian yang dipilih. Selain dari proses penelitian seperti Gambar 1 maka terdapat metode yang digunakan dalam penelitian ini sebagai berikut:

\subsection{Metode Penelitian}

Dalam melakukan pengujian usability menggunakan teknik heuristic evaluation maka metode yang digunakan adalah metode deskriptif. Penggunaan metode ini karena metode deskriptif dapat menjelaskan sebuah keadaan atau kejadian [17]. Begitu juga pengujian usability dengan teknik heuristic evaluation merupakan keadaan atau kejadian yang melihat perspektif ahli terhadap sebuah aplikasi. metode deskriptif juga merupakan proses penelitian dengan tujuan untuk menjelaskan atau menjabarkan fenomena dan keadaan yang terjadi sesuai dengan prosedur ilmiah berdasarkan fakta yang dilihat dari sudut pandang peneliti [18].

\subsection{Metode Pengujian}

Sesuai dengan uraian yang telah dikemukakan bahwa dalam melakukan pengujian usability perangkat lunak pembelajaran matematika metode pengujian yang digunakan adalah heuristic evaluation. Heuristic evaluation memiliki instrumen pengujian berupa pernyataan yang harus dijawab oleh ahli. Terdapat sepuluh 
instrumen pernyataan untuk melakukan pengujian dengan heuristic evaluation seperti yang diperlihatkan pada Tabel 1 .

Tabel I Instrumen Pengujian HE

\begin{tabular}{|l|l|l|}
\hline No & Penyataan & Skala \\
\hline 1 & Visibility of system status & $0,1,2,3,4$ \\
\hline 2 & $\begin{array}{l}\text { Match between system and } \\
\text { the real world }\end{array}$ & $0,1,2,3,4$ \\
\hline 3 & User control and freedom & $0,1,2,3,4$ \\
\hline 4 & Consistency and standards & $0,1,2,3,4$ \\
\hline 5 & Error prevention & $0,1,2,3,4$ \\
\hline 6 & $\begin{array}{l}\text { Recognition rather than } \\
\text { recall }\end{array}$ & $0,1,2,3,4$ \\
\hline 7 & $\begin{array}{l}\text { Flexibility and efficiency of } \\
\text { use }\end{array}$ & $0,1,2,3,4$ \\
\hline 8 & $\begin{array}{l}\text { Aesthetic and minimalist } \\
\text { design }\end{array}$ & $0,1,2,3,4$ \\
\hline 9 & $\begin{array}{l}\text { Help users recognize, } \\
\text { diagnose, and recover } \\
\text { from errors }\end{array}$ & $0,1,2,3,4$ \\
\hline 10 & Help and documentation & $0,1,2,3,4$ \\
\hline
\end{tabular}

\section{Keterangan:}

0. : :tidak ada masalah usability

1. :cosmetic problem

2. :minor usability problem; perbaikan diperlukan

3. :major usability problem; perlu ada perbaikan karena berpengaruh pada proses

4. : usability catastrophe; perlu desain ulang Heuristic evaluation (HE) yang dibutuhkan sebagai responden adalah ahli (expert) sehingga kebutuhan responden hanya sedikit. Kajian yang dilakukan [19] menunjukkan jumlah respoden yang diperlukan dalam heuristic evaluation (HE) berjumlah lima evaluator. Sedangkan pendapat lain mengatakan bahwa evaluator yang dibutuhkan tiga sampai dengan lima evaluator [19]. Penentuan jumlah penguji tersebut disebabkan jumlah penguji yang banyak pada heuristic evaluation (HE) akan menimbulkan banyak masalah dan biaya pengujian [20], kondisi tersebut dapat diilustrasikan seperti pada Gambar 2. Ilustrasi jumlah evaluator pada Gambar 2 menunjukkan bahwa semakin tinggi jumlah evaluator maka tingkat kegagalan pengujian heuristic evaluation juga tinggi dan peluang untuk menemukan usability problem semakin rendah. Sedangkan jika jumlah evaluator rendah maka tingkat kesuksesan pengujian heuristic evaluation semakin tinggi dan tingkat penemuan usability problem juga lebih mudah.

Heuristic evaluation dalam melakukan pengujian melibatkan ahli biasaya lima orang ahli. Penentuan jumlah ahli yang terlibat tersebut sesuai dengan beberapa kajian menunjukkan heuristic evaluation melibatkan lima orang ahli dalam proses pengujian [21], [22]. Namun pengujian juga dapat dilakukan dengan jumlah ahli tiga sampai dengan lima ahli [23]. Prinsip dalam pengujian heuristic evaluation sendiri yaitu semakin banyak ahli yang terlibat maka akan menimbulkan banyak permasalahan dan begitu juga sebaliknya. Kondisi tersebut sesuai dengan ilustrasi penentuan jumlah ahli seperti yang diperlihatkan pada Gambar 2 [24]. Untuk itu di dalam penelitian ini yang menjadi ahli dalam pengujian adalah sebanyak lima orang ahli yang terdiri dari tiga orang ahli teknologi informasi dan dua orang ahli mata pelajaran matematika kelas enam sekolah dasar (guru).

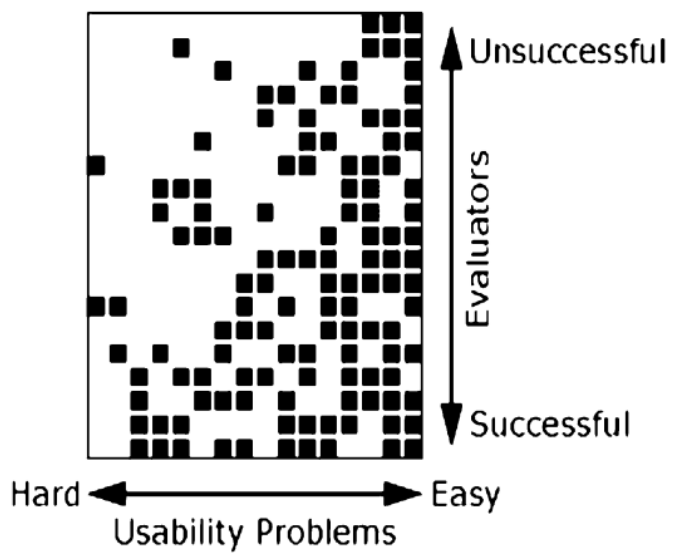

Gambar 2. Penentuan ahli dalam $H E$ [13]

\subsection{Objek Yang Diuji}

Objek pengujian dalam penelitian ini adalah aplikasi atau perangkat lunak mobile mata pelajaran matematika kelas enam. Aplikasi ini memilki berbagai menu diantaranya adalah materi belajar, daftar istilah matematika, latihan soal dan petunjuk penggunaan aplikasi. Selain itu 
juga terdapat materi belajar yang susun berdasarkan bab seperti yang diperlihatkan pada Gambar 3.

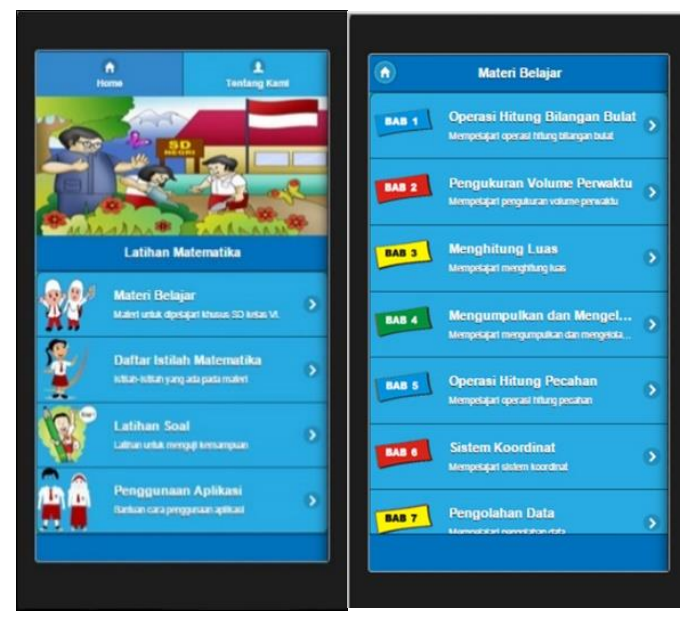

Gambar 3. Menu utama aplikasi dan materi belajar

Untuk melakukan pembelajaran materi matematika maka pengguna dapat mengklik materi pembelajaran dengan cara memilih bab yang ingin dipelajari. Sedangkan untuk melihat daftar istilah matematika dapat mengklik menu daftar istilah. Gambar 4 merupakan tampilan dari salah satu materi pelajaran dan daftar istilah matematika.

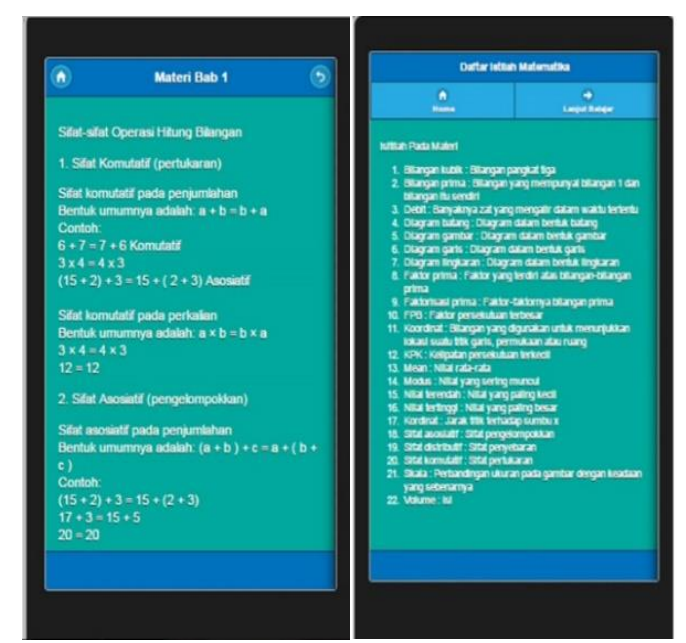

Gambar 4. Detail materi belajar dan istilah

Sedangkan untuk melakukan latihan soal maka pengguna dapat mengklik menu latihan soal. Latihan soal yang diberikan merupakan latihan untuk setiap bab. Gambar 5 dapat dilihat proses latihan yang ada pada aplikasi.

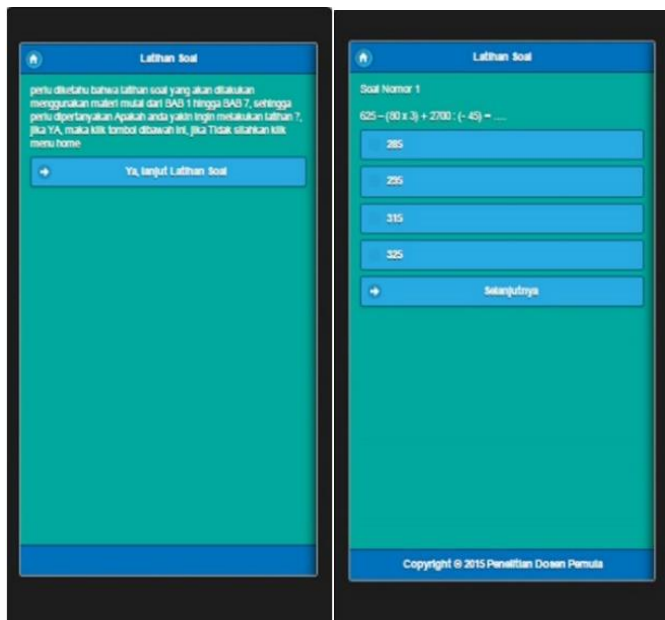

Gambar 5. Proses latihan

\section{HASIL DAN PEMBAHASAN}

Sesuai dengan metode penelian dan proses pengujian aplikasi menggunakan heuristic evaluation yang melibatkan lima orang ahli yang terdiri dari tiga ahli teknologi informasi yaitu dengan simbo A1, A2 dan A2 dan dua ahli dalam mata pelajaran matematika sekolah dasar maka dengan kode A4 dan A5 seperti pada Tabel 2 maka hasil pengujian dapat dijelaskan sebagai berikut:

\subsection{Visibility of system status}

Pernyataan visibility of system status adalah pernyataan yang digunakan untuk melihat bagaimana aplikasi memberikan informasi kepada pengguna ketika proses sedang berjalan [25]. Hasil pengujian yang dilakukan ahli menunjukkan bahwa semua ahli menyatakan pada pernyataan visibility of system status tidak ada masalah usability atau dengan kata lain semua hali memberikan nilai 0 , baik ahli teknologi informasi maupun ahli mata pelajaran matematika (guru). Dengan demikian dapat dikatakan bahwa proses yang berjalan pada aplikasi dapat dilihat oleh pengguna.

\subsection{Match between system and the real world}

Pernyataan match between system and the real world adalah pernyataan untuk mendeskripsikan bahasa yang digunakan didalam sebuah aplikasi, yang dimaksud dengan bahasa tesebut meliputi kata, prase dan konsep yang familiar dengan pengguna [26]. Hasil pengujian 
yang dilakukan oleh ahli menunjukkan bahwa aplikasi yang dibuat telah menggunakan Bahasa yang sesuai. Kondisi tersebut dapat tercermin dari hasil pengujian empat ahli memberikan penilaian 0 dan satu ahli memberikan penilaian 1. Dari hasil penilaian tersebut jika dilihat nilai rerata yaitu 0.2 yang berarti aplikasi tidak memiliki masalah usability jika dilihat dari match between system and the real world.

\subsection{User control and freedom}

Pernyataan user control and freedom adalah pernyataan untuk melihat bagaimana keleluasaan pengguna dalam menggunakan aplikasi. Keleluasaan tersebut meliputi melakukan undo dan redo atau melakukan proses dan pem batalan proses [27]. Dari penilaian ahli menyatakan bahwa dua orang ahli teknologi informasi memberikan penilaian 1 dan satu orang ahli memberikan nilai 0 , sedangkan ahli dari guru mata pelajaran keduanya memberikan penilaian 0 . Dengan demikian secara keseluruhan penilaian ahli mengatakan bahwa aplikasi pembelajaran matematika tidak memiliki masalah usability yang dibuktikan dengan rerata nilai sebesar 0.4.

\subsection{Consistency and standards}

Pernyataan consistency and standards adalah penyataan untuk melihat bagaimana gambar, icon atau kata yang digunkan pada aplikasi memiliki makna yang standar atau tidak membingungkan pengguna sehingga tidak terjadinya kesalahan yang dilakukan oleh pengguna [28]. Pada pernyataan ini ahli tiga ahli memberikan penilaian 0 dan dua hali memberikan nilai 1 . Dua ahli yang memberikan penilaian 1 adalah satu orang ahli dari teknologi informasi dan satu orang ahli dari guru mata pelajaran. Dengan demikian dapat dikatakan untuk consistency and standards secara umum mendapatkan penilaian 0.4 atau tidak memiliki masalah usability.

\subsection{Error prevention}

Pernyataan error prevention adalah pernyataan untuk melihat bagaimana tingkah laku dari aplikasi dalam melakukan pencegahan kesalahan yang akan dilakukan oleh pengguna [29]. Pernyataan ini semua ahli berpandangan bahwa aplikasi memiliki pencegahan yang baik, kondisi tersebut dapat dilihat semua ahli memberikan penilaian 0 baik ahli teknologi informasi maupun ahli mata pelajaran (guru). Dengan demikian dalam hal error prevention tidak terdapat masalah usability pada aplikasi.

\subsection{Recognition rather than recall}

Pernyataan cecognition rather than recall adalah pernyataan untuk melihat bagaimana aplikasi dalam mengurangi memori pengguna. Pengurangan memori pengguna yang dimaksud adalah kemampuan aplikasi dalam mengurangi pengguna dalam mengingat mak dari gambar, pilihan atau keterngan yang ada pada aplikasi [30]. Dalam pernyataan ini penilaian ahli teknologi informasi bahwa aplikasi tidak memiliki masalah usability atau memberikan penilaian 0. Sedangkan ahli mata pelajaran (guru) menganggap aplikasi memiliki cosmetic problem atau memberikan penialai 1 . Namun secara umum dari nilai semua ahli didapat nilai rerata yaitu 0.4 atau jika dibulatkan adalah 0 yang berarti tidak ada masalah usability.

\subsection{Flexibility and efficiency of use}

Pernyataan flexibility and efficiency of use adalah pernyataan untuk melihat apakah aplikasi dapat membantu dalam meringankan pekerjaan secara lebih efektif dan efisien atau dengan kata lain aplikasi memiliki fitur yang dapat dengan mudah dilakukan jika dibandingkan dengan cara konvensional [31]. Untuk itu penilaian ahli terhadap aplikasi menyatakan bahwa terdapat cosmetic problem, dengan kata lain bahwa ahli memberikan nilai 1 terhadap aplikasi yang perlu dipehatikan oleh penyedia aplikasi.

\subsection{Aesthetic and minimalist design}

Pernyataan aesthetic and minimalist design adalah pernyataan untuk melihat komponen dari aplikasi baik itu menu atau informasi yang dibuat apakah memiliki nilai relevansi dengan pengguna [32]. Dari penilaian ahli baik ahli teknologi informasi maupun ahli mata pelajaran (guru) memberikan nilai 0 untuk pernyataan ini. dengan demikian maka dapat dikatakan bahwa aplikasi memiliki komponen menu dan informasi yang 
relevan dengan pengguna atau tidak ada masalah usability dalam bidang ini.

\subsection{Help users recognize, diagnose, and recover from errors}

Pernyataan help users recognize, diagnose, and recover from errors adalah pernyataan untuk melihat aplikasi dalam hal penampilan kesalahan dalam proses dan bagaimana pengguna mengatasi dari kesalahan yang dibuat [33]. Penilaian ahli dalam pernyataan medapatkan nilai rerata sebesar 0.6 atau dibulatkan mendapatkan nilai 1 yang berarti aplikasi memiliki masalah usability dalam bidang cosmetic problem dalam instrumen help users recognize, diagnose, and recover from errors. Penilaian tersebut meliptui tida orang ahli memberikan nilai 1 dan dua orang ahli memberikan nilai 0 .

\subsection{Help and documentation}

Pernyataan help and documentation adalah pernyataan untuk melihat aplikasi memiliki kemapuan untuk digunakan oleh pengguna tanpa harus membaca dokumentasi aplikasi atau membutuhkan bantuan dalam mengoperasikan aplikasi [34]. Pada pernyataan ini penilaian yang diberikan ahli adalah 0 . Penilaian 0 tersebut diberikan oleh semua ahli baik ahli teknologi informasi maupun ahli mata pelajaran (guru). Dengan demikian dapat dikatakan bahwa aplikasi dalam hal help and documentation tidak memiliki masalah usability sama sekali.

Tabel 2. Rekapitulasi Penilaian Ahli

\begin{tabular}{|c|c|c|c|c|c|c|}
\hline No & A1 & A2 & A3 & A4 & A5 & Rerata \\
\hline P1 & 0 & 0 & 0 & 0 & 0 & 0 \\
\hline P2 & 0 & 0 & 1 & 0 & 0 & 0.2 \\
\hline P3 & 1 & 1 & 0 & 0 & 0 & 0.4 \\
\hline P4 & 0 & 0 & 1 & 1 & 0 & 0.4 \\
\hline P5 & 0 & 0 & 0 & 0 & 0 & 0 \\
\hline P6 & 0 & 0 & 0 & 1 & 1 & 0.4 \\
\hline P7 & 1 & 1 & 1 & 1 & 1 & 1 \\
\hline P8 & 0 & 0 & 0 & 0 & 0 & 0 \\
\hline P9 & 1 & 0 & 0 & 1 & 1 & 0.6 \\
\hline P10 & 0 & 0 & 0 & 0 & 0 & 0 \\
\hline
\end{tabular}

Nilai Rerata Akhir

0.3

\section{SIMPUL DAN SARAN}

Sesuai dengan tujuan penelitian yaitu melakukan pengujian heuristic evaluation terhadapat aplikasi pembelajaran matematika anak sekolah dasar maka dapat disimpulkan beberapa hal yaitu:

1. Secara keseluruhan aplikasi yang disediakan tidak memiliki masalah usability atau mendapatkan nilai 0 dari ahli. $\mathrm{T}$

2. Terdapat dua aspek yang mendapat penilaian memiliki cosmetic problem yaitu untuk pernyataan nomor tujuh dan nomor Sembilan sehingga memerlukan perhatian bagi pengembang dalam bidang flexibility and efficiency of use dan help users recognize, diagnose, and recover from errors.

3. Pengembang aplikasi dapat melakukan publikasi aplikasi karena tidak ada masalah yang signifikan dalam hal usability pada aplikasi.

\section{SARAN}

Saran yang dapat diberikan kepada peneliti yang lain adalah hendaknya melakukan pengujian dengan teknik yang lain baik dalam bidang usability ataupun kepuasan pengguna agar mendapatkan hasil yang maksimal sebagai masukan untuk perbaikan atau pengembangan aplikasi.

\section{REFERENSI}

[1] L. Hakim, "Pemerataan Akses Pendidikan Bagi Rakyat Sesuai Dengan Amanat Undang-Undang Nomor 20 Tahun 2003 Tentang Sistem Pendidikan Nasional," EduTech J. Ilmu Pendidik. dan Ilmu Sos., vol. 2, no. 1, 2016.

[2] E. Irawati and W. Susetyo, "Implementasi Undang-Undang Nomor 20 Tahun 2003 Tentang Sistem Pendidikan Nasional Di Blitar," J. Supremasi, vol. 7, no. 1, p. 3, 2017.

[3] E. S. Wahyuni and Y. Yokhebed, "Deskripsi Media Pembelajaran Yang Digunakan Guru Biologi Sma Negeri Di Kota Pontianak," J. Pendidik. Inform. dan 
Sains, vol. 8, no. 1, p. 32, 2019, doi: 10.31571/saintek.v8i1.1105.

[4] M. R. Yamin, "Implementasi Metode Pembelajaran Mind Mapping Untuk Meningkatkan Aktivitas dan Hasil Belajar Peserta Didik pada Pembelajaran Biologi Kelas XI IPA 3 SMAN 1 Pinrang," Biol. Teach. Learn., vol. 2, no. 1, 2019.

[5] F. Rahmawati, "Pengaruh Pendekatan Pendidikan Realistik Matematika dalam Meningkatkan Kemampuan Komunikasi Matematis Siswa Sekolah Dasar," Pros. SEMIRATA 2013, vol. 1, no. 1, 2013.

[6] C. A. Haris, B. S. WA, and A. Nasiri, "PENERAPAN MODEL UTAUT2 UNTUK MENGEVALUASI APLIKASI RUANG GURU," JurTI (Jurnal Teknol. Informasi), vol. 3, no. 2, pp. 192-199, 2019.

[7] S. Fajarwati, "Media pembelajaran animasi swishmax sebagai alternatif untuk siswa SD yang berkesulitan belajar pada materi bangun ruang," Probisnis, vol. 9, no. 1, 2016.

[8] D. Maryani, "Pembuatan media pembelajaran interaktif bangun ruang matematika," Speed-Sentra Penelit. Eng. dan Edukasi, vol. 6, no. 2, 2013.

[9] N. R. Riyadi, "PENGUJIAN USABILITY UNTUK MENINGKATKAN ANTARMUKA APLIKASI MOBILE MYUMM STUDENTS," Sist. J. Sist. Inf., vol. 8, no. 1, pp. 226-232, 2019.

[10] S. Suyanto and U. Ependi, "Pengujian Usability dengan Teknik System Usability Scale pada Test Engine Try Out Sertifikasi," MATRIK J. Manajemen, Tek. Inform. dan Rekayasa Komput., vol. 19, no. 1, pp. 62-69, 2019.

[11] T. Xie, H. Chen, J. Li, and H. Xiong, "A study on the methods of software testing based on the design models," in 2011 6th International Conference on Computer Science \& Education (ICCSE), 2011, pp. 111-113.

[12] U. Ependi, A. Putra, and F. Panjaitan, "Evaluasi tingkat kebergunaan aplikasi Administrasi Penduduk menggunakan teknik System Usability Scale," Regist. J. Ilm. Teknol. Sist. Inf., vol. 5, no. 1, pp. 6376, 2019.

[13] U. Ependi, T. B. Kurniawan, and F.
Panjaitan, "SYSTEM USABILITY SCALE VS HEURISTIC

EVALUATION: A REVIEW," Simetris J. Tek. Mesin, Elektro dan Ilmu Komput., vol. 10, no. 1, pp. 65-74, 2019.

[14] U. Ependi, "Heuristic Evaluation for Mobile Application (Studi Kasus: Aplikasi Depo Auto 2000 Tanjung Api Api Palembang)," Simetris J. Tek. Mesin, Elektro dan Ilmu Komput., vol. 8, no. 2, pp. 563-570, 2017.

[15] I. K. Dewi, Y. T. Mursityo, and R. R. M. Putri, "Analisis Usability Aplikasi Mobile Pemesanan Layanan Taksi Perdana Menggunakan Metode Webuse dan Heuristic Evaluation," J. Pengemb. Teknol. Inf. dan Ilmu Komput. e-ISSN, vol. 2548, p. 964X, 2018.

[16] P. Krisnayani, I. K. R. Arthana, I. G. M. Darmawiguna, and S. Kom, "Analisa Usability Pada Website UNDIKSHA Dengan Menggunakan Metode Heuristic Evaluation," KARMAPATI (Kumpulan Artik. Mhs. Pendidik. Tek. Inform., vol. 5, no. 2, pp. 158-167, 2016.

[17] U. Ependi and N. Oktaviani, "Abstract Keyword Searching with Knuth Morris Pratt Algorithm," Sci. J. Informatics, vol. 4, no. 2, pp. 150-157, 2017.

[18] F. Syakti, "Sistem Informasi Geografis Penderita Malaria pada Kelurahan Cereme Taba Kota Lubuklinggau," Digit. Zo. J. Teknol. Inf. dan Komun., vol. 10, no. 2, pp. 178-188, 2019.

[19] R. Agarwal and V. Venkatesh, "Assessing a firm's web presence: a heuristic evaluation procedure for the measurement of usability," Inf. Syst. Res., vol. 13, no. 2, pp. 168-186, 2002.

[20] S. Hermawati and G. Lawson, "Establishing usability heuristics for heuristics evaluation in a specific domain: Is there a consensus?," Appl. Ergon., vol. 56, pp. 34-51, 2016.

[21] R. Firmansyah, "Evaluasi Heuristik Pada Desain Interface Aplikasi My Indihome," in Seminar Nasional Ilmu Pengetahuan dan Teknologi Komputer, 2016, pp. 69INF.

[22] S. Saifulloh and N. Asnawi, "Evaluasi Desain Antarmuka Dengan Pendekatan Kemudahan Penggunaan (Studi Kasus Mobile App Sport Galaxy Center)," Data 
Manaj. dan Teknol. Inf., vol. 16, no. 4, pp. 55-58, 2015.

[23] A. Z. Abdillah, "Uji Usability Manajemen Arsip Digital Menggunakan Cloud Computing di PT. XYZ." Doctoral Dissertation, Universitas Airlangga, Surabaya, 2015.

[24] J. R. Lewis, "Usability: lessons learned... and yet to be learned," Int. J. Hum. Comput. Interact., vol. 30, no. 9, pp. 663684, 2014.

[25] K. Islam and D. A. Rahayu, "Evaluasi Antarmuka Website Tokopedia menggunakan Metode Heuristic," ENERGY, vol. 8, no. 1, pp. 33-38, 2018.

[26] F. N. Muhammad, "Evaluasi Desain Antarmuka Aplikasi Mobile BPJS Ketenagakerjaan Menggunakan Heuristic Evaluation." Universitas Brawijaya, 2017.

[27] N. Wahid, "Persepsi Pemustaka Terhadap Opac (Online Public Access Catalogue) Di Perpustakaan Fakultas Kedokteran UGM Yogyakarta," UNILIB J. Perpust., vol. 5, no. 1, pp. 34-42, 2019.

[28] I. Khairina and N. H. W. Suprapto, "Analisis Usability pada Website Jawa Timur Park Group dengan Heuristic Evaluation," J. Pengemb. Teknol. Inf. dan Ilmu Komput. e-ISSN, vol. 2548, p. 964X, 2017.

[29] D. P. Restuputri and W. F. Mufti, "Penggunaan Uselearn Sebagai Metode Evaluasi Usability untuk E-Learning," $J$. Tek. Ind., vol. 15, no. 2, pp. 136-144, 2016.

[30] F. Angesti, E. M. A. Jonemaro, and I. Arwani, "Evaluasi Usability Mobile Game Pokemon Go Menggunakan Metode Heuristic," J. Pengemb. Teknol. Inf. dan Ilmu Komput. e-ISSN, vol. 2548, p. 964X, 2018.

[31] S. V. N. Fitri, O. Juwita, and T. Dharmawan, "ANALISIS USER INTERFACE TERHADAP WEBSITE AKTA ONLINE BANYUWANGI MENGGUNAKAN METODE HEURISTIC EVALUATION," INFORMAL Informatics J., vol. 4, no. 3, pp. 103-107, 2020.

[32] N. D. Supriyono, A. Aziz, and W. Harianto, "ANALISIS USER INTERFACE DAN USER
EXPERIENCE PADA GAME PERANG KOMANDO MENGGUNAKAN METODE HEURISTIC

EVALUATION," Semnas SENASTEK Unikama 2019, vol. 2, 2019.

[33] Z. Y. Mubarak, M. N. Sasongko, and H. Syafei, "ANALISIS USABILITAS SISTEM INFORMASI AKADEMIK DI STIKES AL-IRSYAD ALISLAMIYYAH CILACAP," SEMNASTEKNOMEDIA ONLINE, vol. 6, no. 1, pp. 1-8, 2018.

[34] M. R. Faturochman, "PENGUKURAN TINGKAT USABILITY WEBSITEPALAYANGANRIVER. COM DENGAN KONSEPHEURISTICS EVALUATION (Studi kasus: PT. RIVERNUSA JELAJAH ASIA)." Universitas Pasundan, 2019. 